\title{
Relationship between Chinese Traditional Virtues and Psychological Health of University Students
}

\author{
Yi Xiaoming \\ Mental Health Education center \\ Normal University of Neijiang \\ Neijiang, Sichuan 641112, China
}

\begin{abstract}
To investigate the relationship between Chinese traditional virtues and psychological health of university students, 787 university students have been tested with Chinese Virtues Questionnaire and SCL-90 symptom scale. The results show Chinese traditional virtues are character strength under the Chinese cultural background. During its development process, there is gender and age difference in university students and the overall development demonstrates a growing trend. Shaping the characters of Chinese traditional virtues can promote the psychological health level in university students.
\end{abstract}

Keywords-University students; Chinese traditional virtues; psychological health

\section{INTRODUCTION}

In recent years, the psychological health of university students has become a social focus. The study of Xiao Yongchun et al. (2005) indicated that the overall psychological health condition of university students has demonstrated a relatively good trend, and three major aspects, including psychological support, handling measure and personality factors can predict their psychological health condition well[1]. Zhao Yunlong and Zhao Jianxin (2011) adopted regressive analysis and structural equation to analyze and establish the relation model among personality, handling measure and psychological health, and pointed out that the stability, assertiveness, imaginativeness, anxiety and tonicity had obvious positive or negative forecasting impact on the individual psychological health level[2]. Individual personality can cast indirect impact on the individual psychological health through handling measure. Hu Junsheng, Wang Dengfeng and Teng Lanfeng (2007) constructed a relation model among personality, handling measure and psychological health, and indicated that the handling measure was closely related to psychological health through correlation analysis and structural equation. In other words, positive handling can forecast psychological health positively while negative handling can forecast psychological health negatively[3]. Each personality dimension impacted on the psychological health directly or indirectly through handling measure. Specifically, the extroversion, behavioral style, interpersonal relationship and attitudes in personality had positive forecasting influence on the positive handling while the behavioral style can also pose positive forecasting influence on the negative handling. Wang Juandi and Yang Xuemei et al. (2011) found through study on 100 medical

[Foundation project] Sichuan University Ideological and political studies institute (SCSZ2017127) students that the overall average SCL-90 score, obsession, depression and phobic factors of medical students were positively correlated to emotional stability[4].

Positive psychology advocates focusing both the negative and positive aspects of personality. In Chinese traditional culture, the Chinese traditional virtues are embodied as character strengths more or less. In other words, the Chinese traditional virtues deeply influence people's psychology as a positive aspect of Chinese personality. Duan Wenjie et al. (2011) combined cultural similarity and difference and acquired the Chinese Virtues Questionnaire which can measure 24 character strengths and 3 merits after psychometrics analysis and test[5]. Zhang Yonghong and Duan Hongjie et al. (2014) studied the adaptation of this questionnaire in Chinese teenager group and found that the Chinese traditional virtues were obviously negatively correlated to anxiety and depression[6]. This paper further discusses the relation between the Chinese traditional virtues and psychological health of university students and specifies the positive influence of Chinese traditional virtues on psychological health, which contributes to promoting in-depth research on Chinese traditional virtues and provides theoretical basis for campus education and psychological health assistance on university students.

\section{RESEARCH METHOD}

\section{A. Subjects}

830 questionnaires are issued in 4 universities in Henan Province and Sichuan Province. After the ineffective questionnaires are eliminated, 787 effective questionnaires are finally collected and the effective recycling rate is $94.9 \%$. Specifically, 326 of these effective questionnaires are from male students, accounting for $41.4 \%$ while 461 of these effective questionnaires are from female students, accounting for $58.6 \%$; the average age is 20.43 years old; 210 of these effective questionnaires are from freshman students, accounting for $26.7 \%, 322$ are from sophomore students, accounting for $29.5 \%, 194$ are from junior students, accounting for $24.6 \%$ while the rest 151 are from senior students, accounting for $19.2 \%$.

\section{B. Research tool}

Chinese Virtues Questionnaire adopts the Chinese merit questionnaire revised by Zhang Yonghong, Duan Wenjie and 
Tang Xiaoqing (2014). This questionnaire adopts Likert 5scale form, from "very unlike me", "unlike me", "neutral", "like me" to "very like me". There are 96 questions in the whole questionnaire and three assessment scale forms: relationship, vitality and conscientiousness. The average score of each assessment scale form represents the score of each merit. The higher the score is the higher advantage the individual enjoys in this merit.

SCL-90 symptom self-evaluation scale. SCL-90 symptom self-evaluation scale adopts the questionnaire compiled by Derogatis, L. R. (1993). This form includes 9 symptom factors: somatization, obsession, interpersonal relationship sensitivity, depression, anxiety, hostility, phobia, bigotry and psychoticism. There are 90 questions in the form and the symptoms are graded into 5 levels based on severity. The higher the score is, the more severe the symptom is.

\section{Procedures}

All the questionnaire surveys are accomplished during class time and the teachers take charge of the test. Some survey researchers respond to the questions of some individuals on site while the others are not on site. Before the survey, the teachers responsible for survey have received training and are provided with questionnaire survey guiding book and implementation manual. Before the survey, the tastes are informed that the survey results are completely confidential and only used in scientific research. The questionnaires are finished on site and then recovered. This study adopts SPSS11.5 to carry out all the statistical analysis. The specific statistical analysis includes: descriptive statistics on collected data; independent sample $\mathrm{t}$ check; variance analysis, post-event check and correlation analysis.

\section{Result statistics}

1) Gender difference in three major merits of Chinese traditional virtues of university students

TABLE I. GENDER DIFFERENCE IN THREE MAJOR MERITS

\begin{tabular}{ccccc}
\hline & Overall & Male & Female & $\mathrm{t}$ \\
\hline Relationship & $3.837 \pm 0.506$ & $3.852 \pm 0.488$ & $3.832 \pm 0.512$ & $0.343(\mathrm{p}=0.731)$ \\
Vitality & $4.393 \pm 0.533$ & $4.513 \pm 0.530$ & $4.357 \pm 0.529$ & $2.519(\mathrm{p}=0.013)$ \\
Conscientiousness & $3.346 \pm 0.520$ & $3.426 \pm 0.490$ & $3.321 \pm 0.527$ & $1.729(\mathrm{p}=0.085)$ \\
\hline
\end{tabular}

The analysis on gender difference in three major merits of Chinese traditional virtues of university students indicates that the difference in vitality and conscientiousness scores of both male and female students is not obvious ( $p>0.05)$; the vitality score of male university students is obviously higher than that of female university students $(\mathrm{p}<0.05)$. By comparison of the average score of all the merits, the vitality score is the highest, and the relationship score is the second while the conscientiousness is the lowest.

2) Analysis on difference in three major merits of Chinese traditional virtues between university students and teenagers

TABLE II. COMPARISON OF THREE MAJOR MERITS OF CHINESE TRADITIONAL VIRTUES BETWEEN UNIVERSITY STUDENTS AND TEENAGERS

\begin{tabular}{cccc}
\hline & $\begin{array}{c}\text { University students } \\
(\mathrm{n} 1=787)\end{array}$ & Teenagers $(\mathrm{n} 2=337)$ & $\mathrm{t}$ \\
\hline Relationship & $3.837 \pm 0.506$ & $3.914 \pm 0.423$ & $-2.31(\mathrm{p}<0.05)$ \\
Vitality & $4.393 \pm 0.533$ & $3.451 \pm 0.468$ & $28.14(\mathrm{p}<0.001)$ \\
& & & $6.55(\mathrm{p}<0.001)$ \\
\hline
\end{tabular}
Note: (1) In university students, 386 are male and 401 are female; in teenagers, 159 are male and 178 are female;
(2) Teenager data are selected from research of Zhang Yonghong etc.

The comparison of three major merits of Chinese traditional virtues between university students and teenagers indicates that the relationship score of university students is obviously lower than that of teenagers $(\mathrm{t}=-2.31, \mathrm{p}<0.05)$ while the conscientiousness and vitality scores of university students are obviously higher than those of teenagers $(\mathrm{p}<0.001)$.

3) Grade difference in three major merits of Chinese traditional virtues of university students

TABLE III. GRADE DIFFERENCE IN THREE MAJOR MERITS OF CHINESE TRADITIONAL VIRTUES OF UNIVERSITY STUDENTS

\begin{tabular}{|c|c|c|c|c|c|c|}
\hline & Freshman & Sophomore & Junior & Senior & $\mathrm{F}$ & Tukey HSD post-event test \\
\hline Relationship & $3.814 \pm 0.458$ & $3.784 \pm 0.473$ & $4.015 \pm 0.491$ & $3.896 \pm 0.849$ & $4.25(\mathrm{p}<0.01)$ & (Junior>Sophomore) \\
\hline Vitality & $4.264 \pm 0.409$ & $4.303 \pm 0.467$ & $4.691 \pm 0.626$ & $4.791 \pm 0.679$ & $17.09(\mathrm{p}<0.001)$ & $\begin{array}{l}(\text { Junior }>\text { Freshman })(\text { Senior }>\text { Freshman }) \\
\text { (Junior }>\text { Sophomore })(\text { Senior }>\text { Sophomore }) \\
\text { (Junior }>\text { Freshman })(\text { Senior }>\text { Freshman })\end{array}$ \\
\hline $\begin{array}{l}\text { Conscientious- } \\
\text { ness }\end{array}$ & $3.233 \pm 0.442$ & $3.256 \pm 0.430$ & $3.622 \pm 0.619$ & $3.790 \pm 0.757$ & $17.22(\mathrm{p}<0.001)$ & (Junior $>$ Sophomore) $($ Senior $>$ Sophomore $)$ \\
\hline
\end{tabular}

The variance analysis result indicates that the grade effect of relationship is obvious $(\mathrm{F}=4.25, \mathrm{p}<0.0)$ and the post-event comparison check indicates that the relationship score of junior students is obviously higher than that of sophomore 
students $(\mathrm{p}<0.001)$; the grade effect of vitality is extremely obvious $(\mathrm{F}=17.09, \mathrm{p}<0.001)$ and the post-event comparison check indicates that the vitality score of junior students is obviously higher than that of freshman and sophomore students $(\mathrm{p}<0.001)$; the vitality score of senior students is obviously higher than that of freshman and sophomore students $(p<0.001)$; the grade effect of conscientiousness is extremely obvious $(\mathrm{F}=17.22, \mathrm{p}<0.001)$ and the post-event comparison check indicates that the conscientiousness score of junior students is obviously higher than that of freshman and sophomore students $(p<0.001)$, and the conscientiousness score of senior students is obviously higher than that of freshman and sophomore students $(\mathrm{p}<0.001)$.

4) Correlation analysis between three major merits of Chinese traditional virtues of university students and overall SCL-90 score and dimensions

TABLE IV. CORRELATION ANALYSIS BETWEEN THREE MAJOR MERITS OF CHINESE TRADITIONAL VIRTUES OF UNIVERSITY STUDENTS AND OVERALL SCL-90 SCORE AND DIMENSIONS

\begin{tabular}{|c|c|c|c|c|c|c|c|c|c|c|}
\hline & $\begin{array}{c}\text { GSI } \\
\mathrm{r}\end{array}$ & $\begin{array}{c}\text { So } \\
\mathrm{r}\end{array}$ & $\begin{array}{c}\mathrm{OC} \\
\mathrm{r}\end{array}$ & $\begin{array}{c}\text { IS } \\
\mathrm{r}\end{array}$ & $\begin{array}{c}\mathrm{De} \\
\mathrm{r}\end{array}$ & $\begin{array}{c}\mathrm{An} \\
\mathrm{r}\end{array}$ & $\begin{array}{c}\text { Ho } \\
\mathrm{r}\end{array}$ & $\begin{array}{c}\text { PA } \\
\mathrm{r}\end{array}$ & $\begin{array}{c}\text { PI } \\
\text { r }\end{array}$ & $\begin{array}{c}\text { Ps } \\
\mathrm{r}\end{array}$ \\
\hline Relationship & $-0.24 * *$ & $-0.26 * *$ & $-0.15^{* *}$ & $-0.19 * *$ & $-0.20 * *$ & $-0.24 * *$ & $-0.25^{* *}$ & $-0.20 * *$ & $-0.28 * *$ & $-0.25 * *$ \\
\hline Vitality & $-0.31 * *$ & $-0.17 * *$ & $-0.28 * *$ & $-0.28 * *$ & $-0.27 * *$ & $-0.25 * *$ & $-0.24 * *$ & $-0.21 * *$ & $-0.23 * *$ & $-0.19 * *$ \\
\hline Conscientious- & $-0.25 * *$ & $-0.16^{* *}$ & $-0.26 * *$ & $-0.26^{* *}$ & $-0.20 * *$ & $-0.20 * *$ & $-0.26^{* *}$ & $-0.13 *$ & $-0.23 * *$ & $-0.22 * *$ \\
\hline
\end{tabular}

ness

It can be seen from Table 4 that the three major merits of Chinese traditional virtues are obviously negatively correlated to overall SCL-90 score and each dimension except conscientiousness and phobia. Therefore, the higher the conscientiousness, vitality and relationship scores are, the lower the overall SCL-90 score and each dimension score are.

5) Pearson correlation analysis between 24 character strengths of Chinese traditional virtues of university students and overall SCL-90 score \& each dimension

TABLE V. PEARSON CORRELATION ANALYSIS BETWEEN24 CHARACTER STRENGTHS OF CHINESE TRADITIONAL VIRTUES OF UNIVERSITY STUDENTS AND OVERALL SCL-90 SCORE \& EACH DIMENSION (N=408)

\begin{tabular}{|c|c|c|c|c|c|c|c|c|c|c|}
\hline & $\begin{array}{c}\text { GSI } \\
r\end{array}$ & $\begin{array}{r}\text { So } \\
\mathrm{r}\end{array}$ & $\begin{array}{r}\mathrm{OC} \\
\mathrm{r}\end{array}$ & $\begin{array}{r}\text { IS } \\
\mathrm{r}\end{array}$ & $\begin{array}{c}\mathrm{De} \\
\mathrm{r}\end{array}$ & $\begin{array}{c}\mathrm{An} \\
\mathrm{r}\end{array}$ & $\begin{array}{c}\text { Ho } \\
\mathrm{r}\end{array}$ & $\begin{array}{c}\mathrm{PA} \\
\mathrm{r}\end{array}$ & $\begin{array}{c}\mathrm{PI} \\
\mathrm{r}\end{array}$ & $\begin{array}{c}\text { Ps } \\
\mathrm{r}\end{array}$ \\
\hline kindness & $-0.18 * *$ & $-0.20 * *$ & -0.07 & $-0.11 *$ & $-0.14 * *$ & $-0.20 * *$ & $-0.18 * *$ & $-0.13 * *$ & $-0.23 * *$ & $-0.21 * *$ \\
\hline teamwork & $-0.19 * *$ & $-0.20 * *$ & -0.09 & $-0.16^{* *}$ & $-0.16 * *$ & $-0.20 * *$ & $-0.20 * *$ & $-0.16^{* *}$ & $-0.24 * *$ & $-0.24 * *$ \\
\hline fairness & $-0.21 * *$ & $-0.24 * *$ & $-0.15 * *$ & $-0.17 * *$ & -0.16 & $-0.22 * *$ & $-0.21 * *$ & $-0.17 * *$ & $-0.22 * *$ & $-0.17 * *$ \\
\hline love & $-0.24 * *$ & $-0.23 * *$ & $-0.15 * *$ & $-0.19 * *$ & $-0.20 * *$ & $-0.22 * *$ & $-0.20 * *$ & $-0.15 * *$ & $-0.28 * *$ & $-0.27 * *$ \\
\hline authenticity & $-0.18 * *$ & $-0.22 * *$ & $-0.13 *$ & $-0.12 *$ & $-0.13 *$ & $-0.18 * *$ & $-0.17 * *$ & $-0.16^{* *}$ & $-0.19 * *$ & $-0.20 * *$ \\
\hline leadership & $-0.12 *$ & $-0.21 * *$ & -0.09 & $-0.12 *$ & -0.10 & $-0.13 * *$ & $-0.19 * *$ & $-0.15 * *$ & $-0.16 * *$ & $-0.14 * *$ \\
\hline forgiveness & $-0.27 * *$ & $-0.21 * *$ & $-0.19 * *$ & $-0.22 * *$ & $-0.22 * *$ & $-0.25 * *$ & $-0.28 * *$ & $-0.21 * *$ & $-0.29 * *$ & $-0.21 * *$ \\
\hline gratitude & $-0.23 * *$ & $-0.21 * *$ & $-0.14 * *$ & $-0.18 * *$ & $-0.20 * *$ & $-0.23 * *$ & $-0.24 * *$ & $-0.20 * *$ & $-0.24 * *$ & $-0.22 * *$ \\
\hline humor & $-0.23 * *$ & $-0.12 *$ & $-0.19 * *$ & $-0.22 * *$ & $-0.18 * *$ & $-0.14 * *$ & $-0.17 * *$ & $-0.15 * *$ & $-0.13 * *$ & $-0.14 * *$ \\
\hline curiosity & $-0.29 * *$ & $-0.16^{* *}$ & $-0.25 * *$ & $-0.29 * *$ & $-0.29 * *$ & $-0.25 * *$ & $-0.22 * *$ & $-0.25^{* *}$ & $-0.24 * *$ & $-0.14 * *$ \\
\hline zest & $-0.28 * *$ & $-0.18 * *$ & $-0.25 * *$ & $-0.25 * *$ & $-0.26 * *$ & $-0.23 * *$ & $-0.18 * *$ & $-0.17 * *$ & $-0.22 * *$ & $-0.19 * *$ \\
\hline creativity & $-0.25 * *$ & $-0.12 *$ & $-0.26 * *$ & $-0.19 * *$ & $-0.17 * *$ & $-0.17 * *$ & $-0.18 * *$ & $-0.19 * *$ & $-0.17 * *$ & $-0.13 * *$ \\
\hline perspective & $-0.25 * *$ & $-0.11 *$ & $-0.28 * *$ & $-0.24 * *$ & $-0.21 * *$ & $-0.17 * *$ & $-0.23 * *$ & $-0.18 * *$ & $-0.18 * *$ & $-0.18 * *$ \\
\hline hope & $-0.30 * *$ & $-0.23 * *$ & $-0.26 * *$ & $-0.29 * *$ & $-0.29 * *$ & $-0.26 * *$ & $-0.27 * *$ & $-0.20 * *$ & $-0.27 * *$ & $-0.22 * *$ \\
\hline social & $-0.26^{* *}$ & $-0.10^{*}$ & $-0.27 * *$ & $-0.25 * *$ & $-0.22 * *$ & $-0.22 * *$ & $-0.18 * *$ & $-0.16 * *$ & $-0.16 * *$ & $-0.16 * *$ \\
\hline beauty & $-0.18 * *$ & $-0.10 *$ & -0.10 & $-0.17 * *$ & $-0.14 * *$ & $-0.15 * *$ & $-0.19 * *$ & $-0.14 * *$ & $-0.12 *$ & $-0.11 *$ \\
\hline bravery & $-0.28 * *$ & $-0.17 * *$ & $-0.24 * *$ & $-0.25^{*}$ & $-0.24 * *$ & $-0.23 * *$ & $-0.23 * *$ & $-0.21 * *$ & $-0.22 * *$ & $-0.22 * *$ \\
\hline belief & $-0.25 * *$ & $-0.11 *$ & $-0.23 * *$ & $-0.22 * *$ & $-0.23 * *$ & $-0.23 * *$ & $-0.17 * *$ & $-0.12 *$ & $-0.21 * *$ & $-0.11 *$ \\
\hline judgment & $-0.19 * *$ & $-0.13^{*}$ & $-0.23 * *$ & $-0.20 * *$ & $-0.16^{* *}$ & $-0.15 * *$ & $-0.21 * *$ & $-0.12 *$ & $-0.20 * *$ & $-0.19 * *$ \\
\hline prudence & $-0.12 *$ & $-0.16 * *$ & $-0.11^{*}$ & $-0.14 * *$ & $-0.12 *$ & $-0.13 * *$ & $-0.24 * *$ & -0.07 & $-0.14 * *$ & $-0.17 * *$ \\
\hline regulation & $-0.24 * *$ & $-0.13 * *$ & $-0.24 * *$ & $-0.25^{*}$ & $-0.20 * *$ & $-0.20 * *$ & $-0.23 * *$ & $-0.13 * *$ & $-0.19 * *$ & $-0.19 * *$ \\
\hline perseverance & $-0.22 * *$ & $-0.16^{* *}$ & $-0.21 * *$ & $-0.23 * *$ & $-0.19 * *$ & $-0.13 * *$ & $-0.20 * *$ & $-0.13 * *$ & $-0.21 * *$ & $-0.19 * *$ \\
\hline learning & $-0.18 * *$ & -0.04 & $-0.19 * *$ & $-0.18 * *$ & $-0.13 * *$ & $-0.13 * *$ & $-0.13 * *$ & -0.08 & $-0.15^{* *}$ & $-0.14 * *$ \\
\hline modesty & $-0.24 * *$ & $-0.15 * *$ & $-0.22 * *$ & $-0.22 * *$ & $-0.18 * *$ & $-0.21 * *$ & $-0.23 * *$ & -0.09 & $-0.20 * *$ & $-0.19 * *$ \\
\hline
\end{tabular}

Note: (1) ** represents $p<0.01$ and * represents $p<0.05$. (2) Relationships coefficients not significant are written in boldface.
(3) GSI: General Symptomatic Index, So: Somatization, OC: Obsessive-Compulsive, IS: Interpersonal sensitivity, De: Depression, An: Anxiety, Ho: Hostility, PA: Photic Anxiety, PI: Paranoid ideation, Ps: Psychoticis

It can be seen from Table 5 that in the correlation between 24 character strengths of Chinese traditional virtues of university students and overall SCL-90 score \& each dimension, the learning character is not significantly correlated to somatization; teamwork, leadership and beauty are not significantly correlated to obsession symptoms; leadership is not significantly correlated to depression; prudence, learning, modesty are not significantly correlated to phobia Anxiety. But they are all negatively correlated. Other correlations are significantly negative or extremely negative. Therefore, the higher the scores of 24 character strengths are, 
the lower the overall SCL-90 score and each dimension score are.

\section{RESUlT ANALYSIS}

In this study, the scores of three major merits of Chinese traditional virtues in university students are ranked from top to bottom as vitality, relationship and conscientiousness. In the study of Zhang Yonghong et al. (2014) on Chinese teenagers, the scores are ranked from top to bottom as relationship, vitality and conscientiousness. The performances of optimal merits in teenagers and university students are inconsistent. Through further comparison, it is found that the score of university students on relationship is obviously lower than that of teenagers while the scores of university students on vitality and conscientiousness are obviously higher than those of teenagers, which reflects the emotional-oriented character strength of teenagers. As they grow older and step into universities, they demonstrate intelligence-oriented character strength and their strength in conscientiousness becomes more dominant.

There is difference in development stage of character strengths, which can reflect the difference in development tasks and psychological characteristics of university students and teenagers. The gender difference of university students in three major merits of Chinese traditional virtues indicate that the vitality of male university students is obviously higher than that of female university students, which is consistent with the adult research results of Duan Wenjie (2012) under the oriental cultural background[7]. The Chinese teenagers demonstrate different gender difference. Specifically, there is an obvious gender difference in relationship of teenager groups while the gender difference in other two merits is not obvious (2012) [8]. This gender difference might be related to the individual growth and development.

The grade difference analysis on three major merits of Chinese traditional virtues in university students indicates that as students step from freshman to senior, all the three major merits demonstrate an increasing trend. The merits with the largest increase are conscientiousness and vitality. The scores of higher grades are higher than the scores of lower grades and the difference is obvious, indicating that the conscientiousness and vitality in university stage demonstrate an overall fastincreasing trend; concerning the relationship, there is an obvious difference only between junior students and sophomore students, indicating that the relationship in university stage demonstrate a gradually-stable increasing trend. This is consistent with the research outcome of Linley (2007) [9], who tested the British adults and found that the development pace of merits and character strengths were different at different stages but demonstrated an overall lifelong developing trend.

The Chinese traditional virtues consist of 24 character strengths. Experts in positive psychology define the character strengths as a group of positive personality characters reflected by individual cognition, emotion and behavior. This study finds trough correlation analysis that the three major merits of Chinese traditional virtues and 24 character strengths are positively correlated to each dimension of psychological health. In other words, the more dominant the character strengths are, the healthier the psychology is. This study is consistent with the foreign and domestic research outcomes. Peterson (2006) firstly found that the character strengths were obviously positively correlated to psychological health[10]. The researches of Duan Wenjie and Zhang Yonghong (2012, 2014) have confirmed this result. In the meanwhile, this study finds that there is no obvious correlation between some character strengths and psychological health, mainly the obsession and phobia factors, which might be that the formation of obsession and phobia psychological problems is mainly related to pressure and environment.

\section{CONCLUSION}

In the discussion on relation between status quo of Chinese traditional virtues and psychological health of university students, the three major merits and 24 character strengths of Chinese traditional virtues are obviously correlated with psychological health. The Chinese traditional virtues are personality characters labeled by morality, and environmental factors, such as family, society and education, will impact the formation of the virtue characters. As a result, strengthening the environmental impact on positive characters, including family education and campus education, can effectively shape the characters of Chinese traditional virtues and improve psychological health level.

\section{REFERENCES}

[1] Y.C Xiao, M. B Liu, and S. C Gao, "An Investigation on the Mental Health Status of the Students at Fudan University," Fudan Education Forum. vol. 3, pp. 158-166, 2005. (In Chinese)

[2] Y.L Zhao, J. X Zhao,"Study on Relation Between Handling Measure and Psychological Health," China Journal of Health Psychology. vol. 19, pp. 711-713, 2011. (In Chinese)

[3] J.S Hu, D.F Wang, and L.F Teng, “ Relation among Personality, Handling Measure and Psychological Health," Journal of Southwest University (Social Sciences). vol. 33, pp. 28-31, 2007. (In Chinese)

[4] J.D Wang, X.M Yang, B. Ren, M.Y Zhou, and Y. Lin, “ Study on Relation Between Personality Characters and Psychological Health of 100 Medical Students," Journal of Medical Postgraduates, vol. 24, pp. 1290-1293, 2011. (In Chinese)

[5] W.J Duan, Y. Bai, Y.H Zhang , X.Q Tang, Z.Z Wang, and T.T Li, "Study of Applicability of VIA-SI in Chinese University Students ," China Journal of Clinical Psychology, vol. 19, pp. 473-478 2011. (In Chinese)

[6] Y.H Zhang, H.J Duan, X.Q Tang, P. Gan, F.C Gan, and P.F Guo, "Reliability and Validity of Chinese Merit Questionnaires in Teenager Groups," China Journal of Clinical Psychology, vol. 22, pp. 470-474 2014. (In Chinese)

[7] W. Duan, Y. Bai, and X. ang, "Virtues and positive mental health," Hong Kong Journal of Mental Health, vol. 38, pp. 24-31 2012.

[8] W.J Duan, Y. Zhang, and T. Li, "Influence of Parenting Style and Character Strength on Psychology Harmony,"Psychological Exploration, vol. 32, pp. 183-187 2012. (In Chinese)

[9] P.A Linley, J. Maltby, and A.M Wood, “ Character strengths in the United Kingdom:The VIA inventory of strengths," Personality and Individual Differences, vol. 43, pp. 341-351 2007.

[10] C. Peterson, (2006) "Strengths of character and happiness:Introduction to special issue,"Journal of Happiness Studies, vol.7, pp. 289-291 2006. 